\title{
Evidence and What We Make of It
}

\author{
Logan Paul Gage \\ Franciscan University of Steubenville
}

Some prominent epistemologists make a distinction between evidence on the one hand and what is made of that evidence by a subject on the other. For reasons that will become clear, this view threatens the evidentialist project. Yet, as I will argue, it is possible to retain evidentialism while preserving the intuition behind this distinction. First, I will explain this distinction and illustrate it with two examples. Second, I will explain what is at stake for evidentialism. Third, I will develop a possible solution to the problem. I close by considering some likely objections to this solution.

\section{Close to a Truism}

Jonathan Kvanvig is among those who appear to see a distinction between evidence and what is made of that evidence. In fact, Kvanvig writes, "it is something close to a truism that there is both the evidence and what we make of it" (Kvanvig, 2011, p. 53). And Kvanvig is not alone in this. Many Bayesians implicitly affirm this distinction when they distinguish between conditional probabilities on observations and unconditional probabilities of observations.

To illustrate the view of evidence I believe Kvanvig and others have in mind, consider my friend Kraig, a former basketball coach turned philosopher. Recently Kraig and I attended a college basketball game together. According to the Kvanvigian construal of evidence, though we may hold different beliefs Kraig and I largely have the same evidence of what happened during the basketball game. We sat only one seat apart, and we both have good vision. Thus our visual perspective differed only very slightly. Given that I know very little about basketball relative to Kraig, it is unsurprising on the Kvanvigian model to find that Kraig came away with a much greater understanding of that game than I. Our evidence set consisted of nearly identical visual facts; but, given his superior knowledge of the sport and of its individual participants, Kraig took our shared evidence and arranged it into a much more sophisticated understanding of the game. In short, Kraig had the ability to make more of the evidence which was available to us both.

Similarly, say two equally well-informed and well-talented arborists, Amy and Adam, are walking through a forest unfamiliar to either of them. Though the same sensory evidence-visual, olfactory, etc.-is available 


\section{Logan Paul Gage}

to both, Amy and Adam disagree over the proper classification of a tree species they have both just encountered for the first time. Again, we see that in this common construal of evidence the same evidence is shared by both Amy and Adam, and yet they use their individual knowledge and skill (each of which is comparable to the other's knowledge and skill) to form the common evidence into support for incompatible propositions. ${ }^{1}$

\section{The Problem for Evidentialism}

As indicated earlier, lurking behind this seemingly innocuous distinction between evidence and what we make of it is a potential problem for evidentialism. Here is how Kvanvig frames it:

... it is something close to a truism that there is both the evidence and what we make of it. To the extent that what we make of the evidence we have is a function of a perspective with healthy doses of reflective ascent, to that extent there is pressure to think of rationality not solely in terms of one's total body of evidence regarding a target proposition, but also in terms that are less sanguine to the claims of evidentialism. To say that rationality is a function of one's evidence and what one makes of it is, in this way, to say something that goes beyond evidentialism itself. (Kvanvig, 2011, p. 53; [emphasis added])

Recall that at the heart of evidentialism lies the following thesis:

(EJ) Doxastic attitude $D$ toward proposition $p$ is epistemically justified for $S$ at $t$ if and only if having $D$ toward $p$ fits the evidence $S$ has at $t$. (Feldman and Conee, 2004, p. 83)

In other words, epistemic justification is entirely a matter of evidence. Or as Conee and Feldman prefer to put it, epistemic justification "strongly supervenes" on the evidence one has at a given time (Feldman and Conee, 2004, p. 101). Or if one prefers deontological language, what one epistemically ought to believe is solely determined on the basis of one's evidence. $^{2}$

We are now in a position to see the problem: Kvanvig's distinction between evidence and what we make of it is problematic for evidentialism because, contrary to Conee and Feldman's (EJ) thesis, what one epistemically ought to believe at a given time is determined not solely by one's evidence but rather by both the evidence and a host of other, perspectival fac- 


\section{Evidence and What We Make of It}

tors which influence what we make of the evidence. To illustrate, consider the example of the basketball game given earlier. Kraig has much more knowledge of the game of basketball than I ever will. And, on the Kvanvigian model, Kraig and I have roughly the same evidence. So, by (EJ), our doxastic attitude toward the proposition that it was a good game-assuming we have a univocal concept of a 'good game' in mind-should be the same or roughly the same. Otherwise one of us is epistemically unjustified in our doxastic attitude toward this proposition. It is hard to see how evidentialism can be correct, then, when there are so many perspectival factors, none of them necessarily irrational, which affect how I shape our common evidence into my affirmation that it was a good game. Does the evidentialist really want to claim that Kraig and I should have the same doxastic attitude given the numerous ways in which we are likely to differ-say in personality, disposition, and self-trust—which will affect what we make of our common evidence?

Note that this applies to peer disagreement as well. ${ }^{3}$ Kvanvig suggests that it is perfectly rational for perspectival factors like self-trust-in addition to one's evidence - to shape or affect one's doxastic attitude, even when a peer disagrees. ${ }^{4}$ The same evidence was available to both Amy and Adam, the arborists. But, for Kvanvig, it may be perfectly rational, or epistemically justified, for these peers to adopt different doxastic attitudes, because what is epistemically justified involves not only their evidence but also other (not necessarily irrational) factors which shape what Amy and Adam make of the evidence. So here we have a fairly straight-forward denial of the evidentialist thesis (EJ), motivated by the acceptance of the distinction between evidence and what we make of it.

At this stage, some evidentialists are likely to have the following reaction: Surely there is no problem here. All that is required to account for rational disagreement between people with the same immediate evidence is that the two subjects have different prior probability distributions. After all, what matters here is not immediate evidence but total evidence.

This response, while understandable, is nonetheless mistaken. It is true that what matters according to evidentialists is total evidence, including background knowledge. However, notice that background knowledge is not all that is at work: one's personality, disposition, and level of selftrust rightly affect one's doxastic attitudes. Consider again our arborists, Amy and Adam. It seems perfectly possible for Amy to find different parts of their shared evidence more salient than others (with regard to tree classification) without any background belief about the salience of the evidence and without necessarily being irrational. While they both make all of the same sensory observations (i.e., have the same sensory evidence), Amy's 


\section{Logan Paul Gage}

eye is caught by the beauty of the leaves; they just strike her in a way they don't strike Adam and in a way that they might not strike her on another occasion. Because of this, she focuses in on the leaf shape evidence as most salient and decides the new tree's proper classification accordingly. Something about the unique seed structure, however, gets Adam thinking in a direction different from Amy (even though Amy is aware of the seed structure and Adam is aware of the leaf shape). Based on the seed structure of the new tree he classifies it slightly differently. He accords the data from leaf shape some weight but not as much as Amy (and vice versa). To make things more precise, let's stipulate that Amy believes to degree .55 that it is species $x$ and to degree .45 that it is species $y$. Adam believes it is species $x$ with .45 confidence and species $y$ to degree .55 . Plausibly, there is nothing irrational here. Hence, because it still seems possible for two people with the same immediate evidence and the same (relevant) background knowledge to reasonably differ in their doxastic attitudes (or at least in their degrees of belief), evidentialism appears false.

Or perhaps better still, say that Amy and Adam have all the same background knowledge when they gaze upon the new tree in the forest and even find each item of evidence salient to the same degree. Say, for instance, that both of them have seen in textbooks many times a picture of a similar tree. Let us even stipulate that Amy and Adam have the same visual images (for all practical purposes) before their minds when they recall the similar-looking tree in the textbook. On the day they discover the new tree Amy is especially confident in her memorial abilities (though not in a reflective way). Comparing the tree before her to the image in her mind, Amy decides that this is definitely a relative of the tree in the textbook and classifies the new species accordingly. Adam, however, while having the same background evidence (including the same textbook image before his mind, with the same vividness) is not so confident in his memory. ${ }^{5}$ Adam lacks Amy's level of confidence that this new tree is in fact similar to the one in the textbook, even though he is slightly inclined toward Amy's conclusion more than not. Hence he withholds on whether or not this new species is related to the textbook variety and remains non-committal about the best classification for the new tree. To most of us, I suspect, neither Amy nor Adam seem particularly unreasonable. ${ }^{6}$ Importantly, Amy and Adam do not differ in their prior probabilities on any botanical or memorial facts. Nor do they differ with regard to what they find salient. What separates them here is merely their level of confidence in their own abilities.

Still, this may not be enough to mollify our objector. Perhaps one's level of self-trust is simply part of one's background evidence. This sug- 


\section{Evidence and What We Make of It}

gestion has some plausibility in that it is possible for these perspectival factors to become the subject of conscious reflection. For example, in the scenario above, Adam could become aware of the fact that he is not feeling confident and for this reason withhold on the belief in question. In fact, he might become consciously aware of his current lack of confidence, of his past track record in such matters, and even his disposition to self-doubt in such circumstances. For such a person, perspectival factors would constitute part of their evidence. But a little reflection indicates that this would constitute an atypical case. It would take an extremely over-bearing parent, intensive therapy, or serious philosophical training to make the average person aware of these perspectival factors from moment to moment. Perspectival factors of which we are usually unaware affect what is rational to believe. Hence, on the Kvanvigian view of evidencecontra standard evidentialism - an extra-evidential factor seems to affect what is rational to believe.

\section{A Possible Solution}

So far I have presented two ideas. First, the seemingly common sense difference between evidence and what we make of it; and second, Kvanvig's plausible contention that this distinction creates at least a prima facie problem for evidentialism. Given these two ideas, is there any way out for those of us who find evidentialism the most plausible account of epistemic justification? Can both this common sense distinction and evidentialism be preserved? Sadly, I believe the answer is no. Kvanvig has made a compelling case. However, I believe evidentialism and the intuition behind Kvanvig's distinction can be harmonized so as to preserve the plausibility of evidentialism.

I would like to suggest that Kvanvig's common sense distinction can be reinterpreted in the following evidentialist-friendly way. This distinction rests on a faulty notion of what evidence is in the first place. Does evidence exist in the form of objects or events which are 'out there' in the world? This is certainly not the notion of evidence preferred by several paradigmatic defenders of evidentialism. Conee and Feldman advance the following supervenience thesis (S):

(S) The justificatory status of a person's doxastic attitudes strongly supervenes on the person's occurrent and dispositional mental states, events, and conditions. (Conee and Feldman, 2004, p. 56) 


\section{Logan Paul Gage}

Conee and Feldman, then, prefer an internalist understanding of evidence. Evidence consists only of mental states (broadly construed). It does not consist merely in what is out there to be perceived but in one's perceptions. After all, perceptions are all we have to go on when forming doxastic attitudes. As Michael Huemer puts it, "All of your beliefs are inevitably based upon your own mental states..." (Huemer, 2011, p. 28). Indeed, what else could one's beliefs be based upon? As much as we would wish otherwise, we do not have access to raw (i.e., unperceived) data. We have, for better or worse, our own "mental states, events, and conditions."

Given this internalist notion of evidence, does it really make sense to speak of evidence and what we make of the evidence? I don't think so. The distinction collapses once we regard mental states as evidence. Conee and Feldman draw the following mentalist implication (M) from thesis $(\mathrm{S})$ :

(M) If any two possible individuals are exactly alike mentally, then they are alike justificationally, e.g., the same beliefs are justified for them to the same extent. (Conee and Feldman, 2004, p. 56)

So we see that the implication of (S) is that justification supervenes on mental states just as it does on evidence. After all, mental states are our evidence.

Now, given mentalism, must the evidentialist maintain that Kvanvig's distinction is completely mistaken? If so, that seems a bad outcome. For the distinction does seem, as I've said, commonsensical. Fortunately, the mentalist evidentialist need not think Kvanvig too far off the mark. There is still a great role that each one of us, along with our background beliefs, play in shaping or arranging data coming at us from the external world. Yet, I'd like to suggest that this role is pre-evidential-it comes before the mental states which constitute one's evidence. Background beliefs, for instance, are not merely static evidence but also shape further evidence for a subject $S$ by affecting which mental states $S$ has.

Here's how it might look. Kraig and I attend a basketball game and have very similar visual fields. But Kraig, due to his superior knowledge of basketball, actually has different mental states than I do during the game. Given his background beliefs Kraig will amass all sorts of evidence (in the form of mental states) which I will not because of his conceptual framework and prior experiences. The content of his seemings may differ significantly from mine. Say, for instance, the Michigan Wolverines' 


\section{Evidence and What We Make of It}

point guard motions to set up their S-5 play involving a curl screen. They subsequently run the S-5, and their point guard scores a layup. What will Kraig's evidence—in the form of a mental state or 'seeming state'-be? It will seem to Kraig as though the Wolverines ran a successful curl screen. What will my seeming state be? It will seem to me as though the point guard put his hand in the air, and there followed a great deal of movement on the floor before the point guard eventually scored a layup. ${ }^{8}$ Our background beliefs have affected not merely what Kraig and I have done with the raw visual evidence; rather, given our background beliefs, we simply have different evidence in the form of different seeming states. It seems to Kraig as though a successful curl screen has been run. I do not share that seeming in the slightest. In addition to set plays, Kraig will also grasp causal connections, like why a player was substituted, whereas I will only see that a player was substituted. Or again, it will seem to Kraig that a set play has been botched though the Wolverines score whereas it will only seem to me that the Wolverines have scored.

At this point another objection is likely to arise, or rather, the same objection arises again with more conviction: Can't this all be explained by different background evidence rather than different mental states? Kraig is simply able to know that a curl screen was run given his current visual evidence and his prior knowledge of what a curl screen looks like. If this is correct, why posit different mental states?

But let's say for the sake of example that Kraig is daydreaming when the curl screen is run. He sees (roughly) the same visual image that I do, but on this occasion he fails to bring it under the concept of 'curl screen' that he has in his background knowledge. Is Kraig at that moment justified in believing that a curl screen was run during the game? Here it is helpful to distinguish two kinds of justification. Epistemologists often distinguish propositional from doxastic justification. If one has propositional justification for $\mathrm{p}$, then one has good, supporting reasons to believe that $p$-regardless of whether one actually believes that $p$. Doxastic justification for $p$, by contrast, demands that one not merely possess good, supporting reasons for believing $p$ but also that one actually base her belief that $p$ on those supporting reasons. Returning to daydreaming Kraig, it is arguable that he is propositionally justified (i.e., that he possesses good reasons for the belief that 'a curl screen was run during the game'). But surely he is not doxastically justified in believing a curl screen was run. After all, he is not at all aware that it was run. If, after the game, Kraig runs into a fellow basketball enthusiast who asks whether the Wolverines ran a curl screen, would he be justified in believing that one was run? Again, it would seem not—not, at any rate, unless Kraig recalls that visual image from memory 
and is then in the mental state of it seeming to him that a curl screen was run. In other words, the mere visual perception and background knowledge alone are not enough for doxastic justification here. Something else is needed. That something is a mental or seeming state with the content of a curl screen.

Now, how exactly does the fact that Kraig and I have different mental states solve the problem posed to evidentialism by Kvanvig's distinction between evidence and what we make of it? In short, the solution is to recognize that even when it appears that two people have similar evidence for a given proposition $p$, they often do not, for, they may have very different evidence in the form of different seemings. If mental states are evidence, then my evidence itself is different than Kraig's, even though in some important sense we shared the same visual field.

This applies equally well (mutatis mutandis) to our case of arborist peer-disagreement. Background beliefs are not the only factor leading to disparate mental states. While background beliefs are among the most important of factors, surely differences in mood, personality, and other factors also shape one's mental states. So, it is true that there is a common starting place (here, Amy and Adam's visual field). It is also true that there is a sense in which the arborists have 'affected' or 'made something of' the raw data; they bring something to the table which accounts for why they perceive the data differently. But it is crucially important to note that they 'affect' the data pre-evidentially (i.e., before their conscious seemings) by bringing their mood, personality, and level of self-trust to the perception of the data in the first place. This is not typically an active or inferential 'shaping' or 'making of' the evidence but a passive and unconscious one. In sum, despite their peerhood and similar visual images, the evidence possessed by Amy and Adam differs because their mental states differ.

\section{Two Objections}

It is still open to the advocate of the evidence and what we make of it distinction to object along the following lines. If two subjects have the same evidence only when they share the same mental state, do they ever have the same evidence? Do two people ever truly share the exact same mental state? If not, evidentialism seems to amount to the following trivial thesis: If two subjects were to share the exact same mental states - which they never will-they would share the same doxastic justification regarding the same propositions.

While this might at first appear to pose a serious problem for evidentialism, the problem is only apparent. Evidentialism can avoid the triviality concern by noting that the more similar two subjects' mental states 


\section{Evidence and What We Make of It}

are, the more similar their doxastic justification regarding any proposition will be. Evidentialism could thus be falsified if we were to discover a case where two subjects shared similar mental states but were justified in adopting radically different doxastic attitudes toward a proposition $p$. In this way evidentialism remains quite substantive.

Others might fear that my solution lends itself to an unacceptable Humean skepticism. Given my solution, does one ever have access to the 'real world,' or only one's own mental states? If the latter, debilitating skepticism might result. Fortunately, one can accept my proposed solution and even hold to a direct realism which claims that "in cases of normal perception, we are directly aware of something in the external world" (Huemer, 2000, p. 575). True, as Huemer notes, "we cannot perceive of external objects without having perceptual experiences that represent them." But it is a mistake to conclude, as some do,

that we are not really, or not directly, perceiving external objects at all, but only our representations. In fact, perceptual experiences are the "tool" with which we perceive external objects. Their existence no more precludes us from perceiving those objects than the use of an axe precludes the woodcutter from chopping his wood. And just as it would be a mistake to conclude that the man is really chopping his axe, so it is a mistake to conclude that we are really perceiving (or otherwise enjoying awareness of) our perceptual experiences. We perceive external objects by having perceptual experiences - in the sense that those experiences partly constitute our perceiving of external objects.... (Huemer, 2001, p. 81)

In sum, when I claim that evidence consists in mental states, this in no way implies that we cannot be directly aware of objects in the external world. The direct realist can claim that she is directly aware of physical objects ${ }^{9}$ and that (non-inferential) evidence for those objects exists in the form of mental states. The claim that one can be directly aware of a blue light, for example, in no way negates the claim that the evidence for there being a blue light is that one seems to see a blue light.

\section{Conclusion}

If my argument has been successful then I have shown that while Kvanvig's distinction between evidence and what is made of that evidence is ultimately mistaken, the mentalist evidentialist can retain the grain of truth in this distinction. The mentalist evidentialist sees mental states themselves as evidence and can account for cases of disagreement over, say, the same visual field in terms of different mental states (i.e., different 
evidence) rather than different arrangement of shared evidence. Typical evidentialists, then, have internalist (mentalist) resources to deal satisfactorily with the challenge posed by the distinction between evidence and what we make of it. ${ }^{10}$

\section{Notes}

1 See the following section for more on how this process is supposed to work.

2 It is worth noting that the privileging of the standard sense of "epistemic ought"- - see Feldman (2004) — has been challenged by Keith DeRose (2000; 2011). Still, in what follows I retain the standard sense.

3 There are at least two distinct problems of peer disagreement. One concerns how it is possible (if it is indeed possible) for peers with the same (or nearly the same) evidence regarding proposition $p$ to reasonably diverge in their doxastic attitudes toward $p$. Another problem concerns whether and to what extent they should revise their doxastic attitudes (or perhaps their degrees of belief) upon learning of the evidence, credentials, and doxastic attitudes of the other party or parties. In what follows, I am only concerned with the former problem.

${ }^{4}$ Kvanvig believes that self-trust and such factors are best modeled as metaevidence.

5 I'm assuming here that Adam is not obsessive in this regard, in which case we might be tempted to think that this perspectival factor is irrational.

6 I am assuming throughout that, while Amy and Adam come to different conclusions, they have not (yet) discussed their differing conclusions. For once they do, there may be some pressure for both of them - knowing, as they do, the equal expertise of the other-to be much less confident in their judgments or even suspend judgment altogether. See footnote 3 .

7 For the latest debates over this conception of evidence as mental 'seemings' see Tucker (2013).

8 In all seriousness, thanks to Kraig Martin for giving me the example of a curl screen. I have no idea what that is.

9 Awareness, as Huemer (2001, p. 51) points out, is awareness of something-in this case the external world.

${ }_{10}$ I'd like to thank two anonymous reviewers, Trent Dougherty, Lydia McGrew, the Baylor Graduate Philosophy Colloquium, and attendees of the University of Miami's 2011 Graduate Epistemology Conference for helpful feedback.

\section{Works Cited}

Conee, Earl and Richard Feldman. (2004) Internalism Defended. In Earl Conee and Richard Feldman (eds.), Evidentialism: Essays in Epistemology (pp. 5382). New York: Oxford University Press.

DeRose, Keith. (2000) Ought We to Follow Our Evidence? Philosophy and Phenomenological Research 60(33): 697-706. 


\section{Evidence and What We Make of It}

. (2011) Questioning Evidentialism. In Trent Dougherty (ed.), Evidentialism and its Discontents (pp. 137-146). New York: Oxford University Press.

Feldman, Richard. (2004) The Ethics of Belief. In Earl Conee and Richard Feldman (eds.), Evidentialism: Essays in Epistemology (pp. 166-195). New York: Oxford University Press.

Feldman, Richard and Earl Conee. (2004) Evidentialism. In Earl Conee and Richard Feldman (eds.), Evidentialism: Essays in Epistemology (pp. 83-107). New York: Oxford University Press.

Huemer, Michael. (2000) Direct Realism and the Brain-in-a-Vat Argument. Philosophy and Phenomenological Research 61(2): 397-413.

- (2001) Skepticism and the Veil of Perception. Lanham, MD: Rowman \& Littlefield.

- (2011) Epistemological Egoism and Agent-Centered Norms. In Trent Dougherty (ed.), Evidentialism and its Discontents (pp. 17-33). New York: Oxford University Press.

Kvanvig, Jonathan. (2011) The Rational Significance of Reflective Ascent. In Trent Dougherty (ed.), Evidentialism and its Discontents (pp. 34-54). New York: Oxford University Press.

Tucker, Chris, ed. (2013) Seemings and Justification: New Essays on Dogmatism and Phenomenal Conservatism. New York: Oxford University Press. 